\title{
Estimativa da composição iônica da solução do solo a partir da lâmina de água em solo afetado por sais sob cultivo de arroz irrigado
}

\author{
Estimating the ionic composition of soil solution from water table in salt-affected soils growing \\ irrigated rice
}

\author{
Felipe de Campos Carmona ${ }^{\mathrm{I}}$ Ibanor Anghinoni ${ }^{\mathrm{II}}$
}

\begin{abstract}
Este trabalho teve como objetivos avaliar a relação entre a condutividade elétrica e os teores de $\mathrm{Na}^{+}$na lâmina de água e na solução de solos com diferentes níveis de sais, sob o cultivo de arroz irrigado. Foram selecionados solos para o cultivo de arroz com percentagens de sódio trocável de 5,6\%; 9,0\%; $21,2 \%$ e 32,7\%. Previamente à entrada de água nas parcelas, foram instalados coletores de solução do solo nas profundidades de 5, 10, 20 e 40cm. Após o alagamento, foram realizadas coletas semanais, até 91 dias após o início da irrigação, da solução do solo e da lâmina de água, para a análise da condutividade elétrica e dos teores de $\mathrm{Na}^{+}$e $\mathrm{K}^{+}$. Os valores dos atributos da lâmina de água correlacionaram-se positiva e significativamente aos valores da solução do solo, em cada profundidade. A melhor correlação média foi obtida para a condutividade elétrica, portanto, sua estimação na solução do solo pode ser obtida a partir da análise da lâmina de água, com o uso de condutivímetros portáteis.
\end{abstract}

Palavras-chave: condutividade elétrica, sódio, Oryza sativa.

\section{ABSTRACT}

This study aimed to investigate the relationship between electrical conductivity and $\mathrm{Na}^{+}$, and $\mathrm{K}^{+}$in the water table and in the solution of soils with different levels of salinity under flooded rice. For rice cultivation, soils with exchangeable sodium percentages of $5.6 \% \quad 9.0 \% 21.2 \%$ and $32.7 \%$ were selected. Prior to flooding, soil solution collectors were installed at depths of 5, 10, 20 and 40cm. After flooding, soil solution and water layer samples were collected weekly until 91 days after onset of irrigation, for the analysis of electrical conductivity and $\mathrm{Na}^{+}$. The content of these attributes in the water table were related to the values at each depth, and there was a significant positive association for all attributes at all depths. The highest average correlation was obtained for the electrical conductivity, so its estimation in the soil solution can be obtained easily through the water table, using a portable conductivity meter.

Key words: electrical conductivity, sodium, Oryza sativa.

A condutividade elétrica (CE) é o atributo mais utilizado para o monitoramento da salinidade da solução do solo, pela praticidade na medição e alta correlação com o teor de sais solúveis. Esse atributo representa o fenômeno de transferência de eletricidade exercido pelas partículas carregadas, solutos iônicos (cátions e ânions) e coloides, sobre uma força aplicada em um campo elétrico (DONEEN, 1975). Em geral, a CE dos solos cultivados com arroz irrigado aumenta após a submergência, atingindo um máximo e decrescendo para valores estáveis (PONNAMPERUMA, 1972).

Aocorrência de danos ao arroz irrigado está diretamente relacionada com a salinidade da solução do solo na zona radicular (condutividade elétrica efetiva - CEe). O monitoramento da salinidade da solução do solo pode ser feito instantaneamente, utilizando-se coletores de solução, como os propostos por SILVA et al. (2003). Entretanto, dependendo do percentual de silte e de argila do solo, há a possibilidade de entupimento do dispositivo. Além disso, quanto maior a profundidade de instalação do coletor, maior é a energia requerida na sucção, o que pode determinar uma baixa vazão de solução.

Instituto Rio Grandense do Arroz (IRGA), Seção de Agronomia, Av. Bonifácio Carvalho Bernardes, 1494, Bairro Carlos Wilkens, 94930-030, Cachoeirinha, RS, Brasil. E-mail: felipe.c.carmona@gmail.com. Autor para correspondência.

"Programa de Pós-graduação em Ciência do Solo, Universidade Federal do Rio Grande do Sul (UFRGS), Porto Alegre, RS, Brasil. 
Nesse sentido, a medição direta da condutividade elétrica da lâmina de água poderia ser uma alternativa ao uso de coletores de solução, pela relação existente entre a CE da solução do solo e a $\mathrm{CE}$ da lâmina de água. Desse modo, a determinação da expectativa de dano causado pela salinidade da solução do solo à cultura do arroz irrigado poderia ser rapidamente estimada pela simples medida da $\mathrm{CE}$ da lâmina de água. Além disso, esse método poderia ser utilizado também para a estimação da concentração de sódio na solução do solo, já que, nas lavouras das regiões costeiras do Rio Grande do Sul, a concentração desse íon está diretamente relacionada à condutividade elétrica da solução do solo (CARMONA et al., 2011A).

Este trabalho teve como objetivo verificar a correlação entre a condutividade elétrica (CE) e os teores de $\mathrm{Na}^{+}$na lâmina de água e na solução de solos com diferentes níveis de salinidade, cultivados com arroz irrigado.

Otrabalho foi realizado naFazendaCavalhada, em Mostardas - RS, em um Planossolo Háplico distrófico típico. Nessa propriedade, foram selecionadas quatro glebas com níveis crescentes de percentagem de sódio trocável (PST), na camada de 0-20cm: 5,6\% (gleba Casamento), 9,0\% (gleba Cavalhada), 21,2\% (gleba Banhado) e 32,7\% (gleba Sinval).

A semeadura do arroz foi realizada em novembro de 2008 e a colheita em março de 2009. Utilizaram-se as cultivares 'IRGA 417', em três locais, e o seu parental imediato IRGA 422 CL em um dos locais (PST 5,6\%). A densidade de semeadura foi de $120 \mathrm{~kg} \mathrm{ha}^{-1}$ e o espaçamento de $0,2 \mathrm{~m}$ entre linhas. $\mathrm{O}$ controle de plantas daninhas foi feito com herbicidas específicos aplicados no estádio de desenvolvimento V4 (COUNCE et al., 2000).

Os dados deste trabalho foram obtidos a partir de um experimento maior, cujo objetivo principal era o de avaliar a interação entre o manejo diferenciado da adubação potássica e a salinidade do solo (CARMONA et al., 2011B) nas quatro glebas (Casamento, Cavalhada, Banhado e Sinval). O delineamento, naquele estudo, fora de blocos ao acaso, com quatro tratamentos e três repetições. Para o presente estudo, utilizaram-se apenas as parcelas testemunha do experimento original. Essas parcelas tiveram a dimensão de $12 \mathrm{~m}^{2}(4 \mathrm{mx} 3 \mathrm{~m})$, com espaçamento de $0,5 \mathrm{~m}$ entre parcelas e três repetições em cada gleba.

A caracterização inicial dos solos avaliados (TEDESCO et al., 1995) pode ser consultada em CARMONA et al. (2011B). As parcelas nos quatro locais receberam a adição apenas de $\mathrm{N}$, em cobertura, na dose de $120 \mathrm{~kg} \mathrm{ha}^{-1}$, sob a forma de ureia, previamente à entrada da água de irrigação, no estádio de desenvolvimento V4 (66\% da dose) e em V8 (34\% da dose).

Anteriormente ao início da irrigação das áreas experimentais, foram instalados coletores de solução do solo nas parcelas, nas profundidades de $5,10,20$ e $40 \mathrm{~cm}$. A descrição do equipamento e metodologia de coleta foram realizadas conforme proposta de SILVA et al. (2003). Foram coletados aproximadamente $40 \mathrm{~mL}$ de solução por profundidade, em cada coleta. Após as coletas, as alíquotas eram acondicionadas em tubos plásticos com tampa a vácuo. As coletas, tanto de solução do solo, quanto da lâmina de água, foram realizadas a partir do sétimo dia após o início do alagamento (DAA), até 91DAA, com intervalo de sete dias entre as coletas. Após a determinação da condutividade elétrica (CE) das amostras, essas eram acidificadas, para posterior análise dos teores de $\mathrm{Na}^{+}$(TEDESCO et al., 1995).

Utilizaram-se duas fontes de água: a Lagoa do Casamento, para irrigar os experimentos nas glebas denominadas Casamento e Cavalhada; e a Lagoa dos Gateados, nas glebas Banhado e Sinval. A condutividade elétrica e o teor de sódio em ambas as fontes foi baixa e se manteve constante ao longo do estudo, sendo que os valores médios de $\mathrm{CE}$ e $\mathrm{Na}^{+}$ foram de $0,32 \mathrm{dS} \mathrm{m}^{-1}$ e de $0,15 \mathrm{mg} \mathrm{L}^{-1}$, respectivamente, na Lagoa dos Gateados e de $0,19 \mathrm{dS} \mathrm{m} \mathrm{m}^{-1}$ e $0,07 \mathrm{mg} \mathrm{L}^{-1}$, na Lagoa do Casamento.

Os atributos de solução do solo determinados para cada profundidade de amostragem foram correlacionados aos da lâmina de água, utilizando-se o teste de comparação simples de médias pareadas (teste $t$ ), sendo determinado o coeficiente de correlação e sua significância estatística para a verificação do grau de associação entre as variáveis.

Nas quatro profundidades avaliadas, houve alto grau de associação $(\mathrm{P}<0,01)$ entre a $\mathrm{CE}$ da lâmina de água e a CE da solução do solo cultivado com arroz irrigado (Figura 1), sendo que, em média, a associação foi de $r=0,80$. A maior correlação foi observada na profundidade de $5 \mathrm{~cm}$ (Figura 1A), decrescendo com o aumento da profundidade. Em solos alagados e cultivados com arroz irrigado, é esperada uma variação na $\mathrm{CE}$ ao longo do período de alagamento, que tende a aumentar nas primeiras semanas, devido à mobilização do $\mathrm{Fe}^{2+}$ e $\mathrm{Mn}^{2+}$ e à acumulação de $\mathrm{NH}_{4}{ }^{+}$, $\mathrm{HCO}_{3}{ }^{-}$e $\mathrm{RCOO}^{-}$(DEDATTA, 1983). Com o passar do tempo, a CE tende a diminuir, o que pode ser atribuído, em parte, à absorção de íons pelas plantas de arroz e, também, à lixiviação. Entretanto, mesmo com ocorrência de variações ao longo do período de 


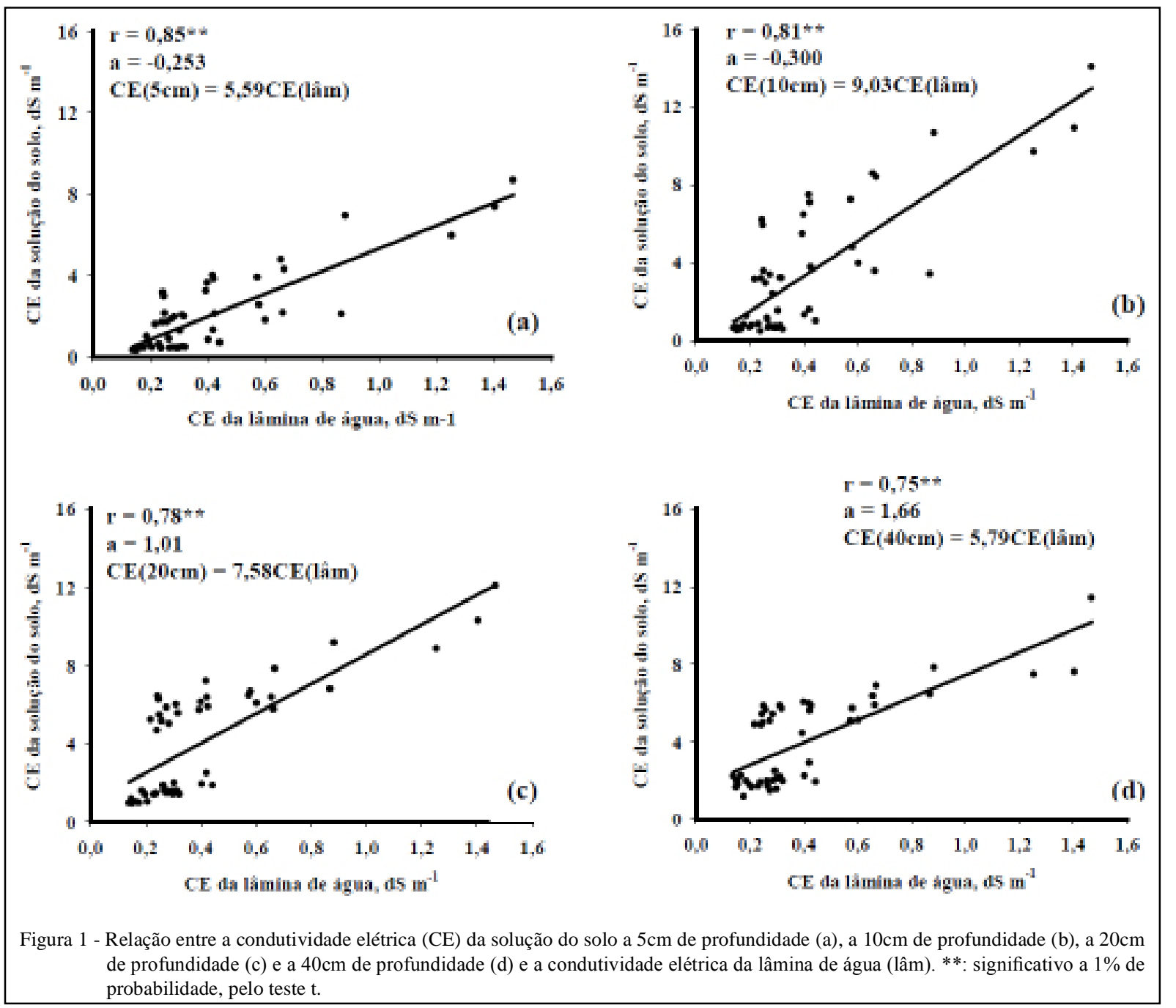

cultivo, a CE da lâmina de água manteve alto grau de associação com a CE da solução do solo, não apenas na camada mais superficial do solo (Figura 1A), mas em todo o perfil avaliado (Figura 1). Isso demonstra haver um gradiente de concentração entre a solução do solo e a lâmina de água, que pode ser considerada boa indicadora da salinidade do solo cultivado com arroz irrigado.

Com relação à variação dos teores de sódio na solução do solo, nas diferentes profundidades avaliadas, verificou-se expressiva variação de valores, o que também foi verificado com o solo em estado oxidado (CARMONA et al., 2011B). À semelhança do que ocorreu com a $\mathrm{CE}$, houve alto grau de associação $(\mathrm{P}<0,01)$ entre os teores de sódio na lâmina de água e na solução do solo e essa correlação foi maior quanto maior a proximidade da amostra de solução com a lâmina de água (Figura 2). Em média, a correlação foi de $r=0,78$, sendo que a associação foi muito semelhante nas profundidades de 10 a $40 \mathrm{~cm}$ (Figura 2B-D). Pelo alto raio de hidratação e baixa demanda pelas plantas, o sódio é considerado um elemento de alta mobilidade no solo e o alagamento proporcionado pelo cultivo de arroz irrigado favorece sua lixiviação no perfil (PONNAMPERUMA, 1981). Essa suposta mobilidade, entretanto, parece não ter influenciado na associação entre os valores do elemento na lâmina de água em relação `a solução do solo, nas diversas profundidades avaliadas (Figura 2).

A CE e os teores de sódio na solução do solo até $40 \mathrm{~cm}$ de profundidade são positivamente correlacionados aos da lâmina de água, sendo o grau de associação com a lâmina de água maior quando relacionado à profundidade de $5 \mathrm{~cm}$. Portanto, a salinidade da solução do solo cultivado com arroz irrigado por alagamento pode ser estimada utilizando-se

Ciência Rural, v.43, n.3, mar, 2013. 

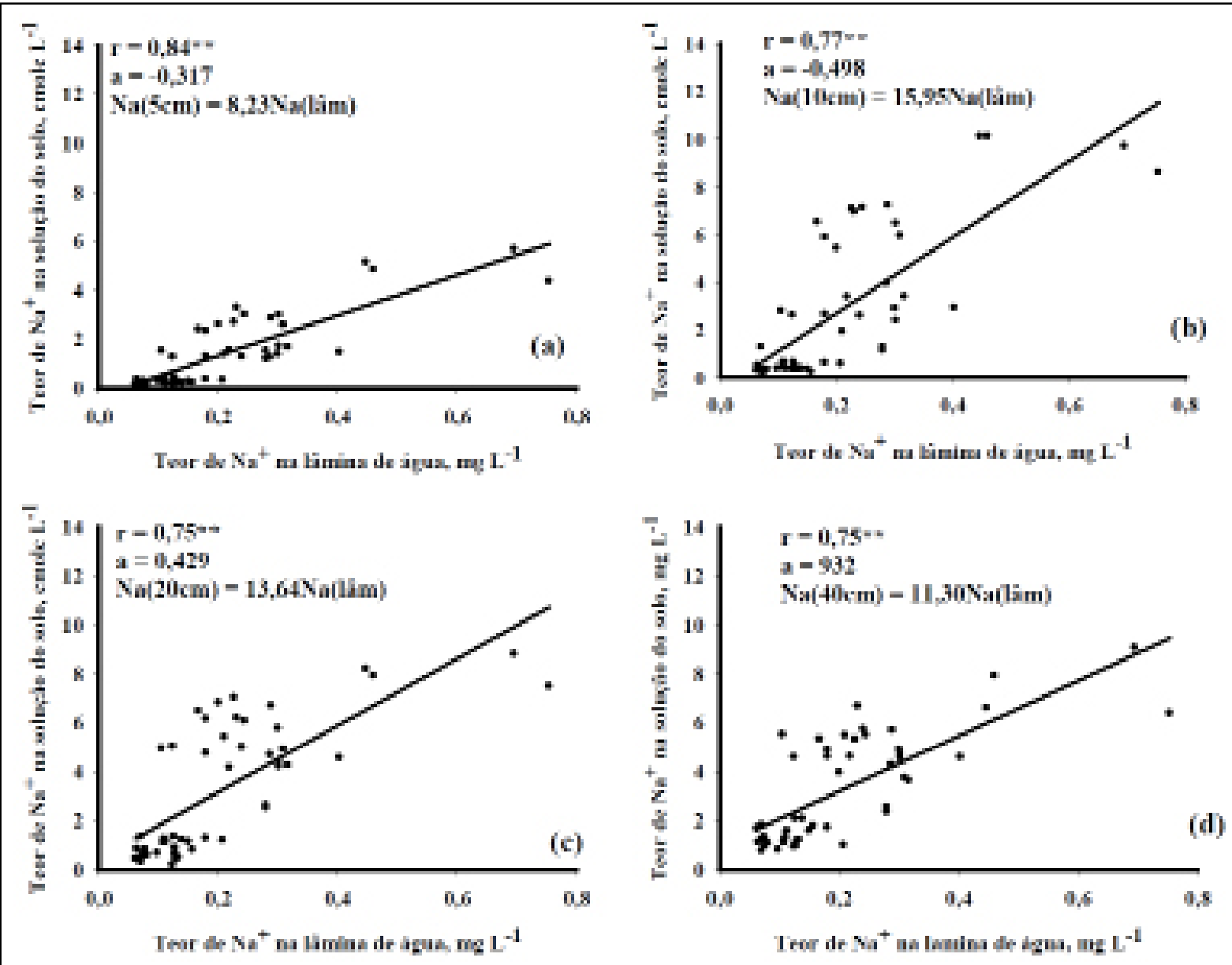

Figura 2 - Relação entre o teor de sódio $\left(\mathrm{Na}^{+}\right)$da solução do solo a $5 \mathrm{~cm}$ de profundidade (a), a $10 \mathrm{~cm}$ de profundidade (b), a $20 \mathrm{~cm}$ de profundidade (c) e a $40 \mathrm{~cm}$ de profundidade (d), e o teor de sódio da lâmina (lâm) de água. **: significativo a $1 \%$ de probabilidade, pelo teste $\mathrm{t}$.

condutivímetros portáteis, de maneira rápida e eficiente, pela análise da lâmina de água. Entretanto, novos estudos se fazem necessários em uma abrangência maior de solos, visto que essas relações podem ser diferentes em função da ampla variação das características químicas, físicas e biológicas dos solos cultivados com arroz irrigado, tanto nas planícies costeiras, quanto nas demais regiões arrozeiras do Rio Grande do Sul. Nesse sentido, devem-se buscar resultados relativos a outros nutrientes altamente demandados pela cultura do arroz, como o fósforo e o nitrogênio.

\section{REFERÊNCIAS}

CARMONA, F.C. et al. Attributes of irrigated rice as affected by soil sodicity and potassic fertilizer application. Revista Brasileira de Ciência do Solo, v.35, n.3, p.889-897, 2011B. Disponível em 〈www.scielo.br/pdf/rbcs/v35n3/v35n3a23.pdf〉. Acesso em: 10 jun. 2010. doi: 10.1590/S0100-06832011000300023.
CARMONA, F.C. et al. Salinidade da água e do solo e seus efeitos sobre o arroz irrigado no Rio Grande do Sul. Cachoeirinha: Instituto Rio-Grandense do Arroz (IRGA), 2011A. 54p. (Boletim Técnico, 10).

COUNCE, P.A. et al. A uniform, objective, and adaptive system for expressing rice development. Crop Science, v.40, n.2, p.436443, 2000. Disponível em: <https://www.crops.org/publications/ cs/articles/40/2/436>. Acesso em: 12 jun. 2010. doi: 10.2135/ cropsci2000.402436x.

DeDATTA, S.K. Principles and practices of rice production. New York: John Wiley, 1983. 681p.

DONEEN, L.D. Salinization of soil by salts in the irrigation water. Transactions of the American Geophysics Union, v.35, p.943950, 1975.

PONNAMPERUMA, F.N. Some aspects of the physical chemistry of paddy soils. In: SYMPOSIUM ON PADDY SOIL, 1981, Pequim. Proceedings... Beijing: Science Press-Springer, 1981. p.59-94. 
PONNAMPERUMA, F.N. The chemical of submerged soils. Advances in Agronomy, v.24, p.29-96, 1972.

SILVA, L.S. et al. Alterações nos teores de nutrientes em dois solos alagados, com e sem plantas de arroz. Ciência Rural, v.33, n.3, p.487-490, 2003. Disponível em: <http://www.scielo. $\mathrm{br} / \mathrm{scielo}$.php? pid=S0103-84782003000300014\& script $=\mathrm{sci}_{-}$ arttext>. Acesso em: 05 abr. 2010. doi: 10.1590/S010384782003000300014 .

TEDESCO, J.M. et al. Análise de solo, plantas e outros materiais. 2ed. (rev. e ampl). Porto Alegre: Departamento de Solos da UFRGS, 1995. 174p. (Boletim Técnico de Solos, 5).

Ciência Rural, v.43, n.3, mar, 2013. 